\title{
PREDIÇÃO DA PROPAGAÇÃO DO SARS-COV-2 NO ESTADO DO AMAPÁ, AMAZÔNIA, BRASIL, POR MODELAGEM MATEMÁTICA
}

\author{
ARTIGO ORIGINAL \\ DIAS, Neylan Leal ${ }^{1}$ \\ SILVA, Edcarlos Vasconcelos da ${ }^{2}$ \\ PIRES, Marcelo Amanajas ${ }^{3}$ \\ CHAVES, Daniel 4 \\ SANADA, Katsumi Letra ${ }^{5}$ \\ FECURY, Amanda Alves ${ }^{6}$
}

\footnotetext{
${ }^{1}$ Matemático, Doutorando em Engenharia Mecânica - FEB/UNESP-SP. Professor e pesquisador do Curso de Matemática da Universidade Federal do Amapá (UNIFAP). 2 Matemático, Doutorando em Saúde Pública - FIOCRUZ/RJ. Docente do Curso de Matemática da Universidade Federal do Amapá (UNIFAP).

${ }^{3}$ Físico, Mestre em Física (UFF), doutorando no Centro Brasileiro de Pesquisas Físicas (CBPF).

${ }^{4}$ Historiador, Doutor em História Comparada, Professor e pesquisador do Curso de História, dos Programas de Pós-Graduação em Desenvolvimento Regional e em Propriedade Intelectual e Transferência de Tecnologia para a Inovação, Universidade Federal do Amapá (UNIFAP).

${ }^{5}$ Letras, Mestre em Ciência da Educação (UNIFAL) Docente do Instituto Federal do Amapá (IFAP).

${ }^{6}$ Biomédica, Doutora em Doenças Tropicais, Professora e pesquisadora do Curso de Medicina da Universidade Federal do Amapá (UNIFAP).
} 
DIAS, Cláudio Alberto Gellis de Mattos $^{7}$

OLIVEIRA, Euzébio de ${ }^{8}$

DENDASCK, Carla Viana ${ }^{9}$

LEAL, Simone Delphim ${ }^{10}$

DIAS, Neylan Leal. Et al. Predição da propagação do SARS-CoV-2 no Estado do Amapá, Amazônia, Brasil, por modelagem matemática. Revista Científica Multidisciplinar Núcleo do Conhecimento. Ano 05, Ed. 05, Vol. 06, pp. 73-95. Maio de 2020. ISSN: 2448-0959,

Link de acesso: https://www.nucleodoconhecimento.com.br/saude/predicao-da-propagacao

\section{RESUMO}

Este artigo apresenta uma análise da propagação do SARS-CoV-2 no Amapá através da utilização de três abordagens. Na primeira, partiu-se do modelo ICL para a pandemia aplicado ao Brasil para implementação de uma projeção comparada linear para a população amapaense. A segunda abordagem foi desenvolvida com a solução de curto prazo do modelo SIR padrão onde mostrou-se que o típico comportamento exponencial descreve satisfatoriamente os dados para as primeiras semanas da epidemia, mas logo após ocorrem discrepâncias precoces em decorrência de uma desaceleração brusca na evolução temporal do número de casos devido a medidas

7 Biólogo, Doutor em Teoria e Pesquisa do Comportamento, Professor e pesquisador do Colegiado de Química, Campus Macapá, Instituto Federal do Amapá (IFAP).

8 Biólogo, Doutor em Doenças Topicais, Professor e pesquisador do Curso de Educação Física da Universidade Federal do Pará (UFPA).

9 Teóloga, Doutora em Psicanálise, pesquisadora do Centro de Pesquisa e Estudos Avançados- CEPA.

10 Matemática, Doutora em Modelagem Computacional, Professora e pesquisadora do Curso de Matemática da Universidade Federal do Amapá (UNIFAP). 
de isolamento. Esse novo regime é apropriadamente descrito com a terceira abordagem que é baseada no modelo vSIR que é em uma variante do modelo SIR. Os resultados apresentados possibilitam, por um lado, uma melhor compreensão dos cenários já enfrentados pela população e por outro lado fornecem projeções de curto prazo que estarão sendo constantemente atualizadas no link[11].

Palavras-chave: COVID-19, pandemia, modelo matemático, vSIR, SARS-CoV-2.

\section{INTRODUÇÃO}

Coronavírus é uma família de vírus que causam infecções respiratórias com que embora tenham registros desde 1937, somente em 31 de dezembro de 2019, após casos registrados na China o novo coronavírus foi descoberto e identificado como o causador da doença chamada COVID-19 que é causada pelo coronavírus SARS-CoV2 (MINISTÉRIO DA SAÚDE, 2020b).

De acordo com a Organização Mundial de Saúde (OMS), cerca de $80 \%$ dos casos podem ser assintomáticos e os $20 \%$ restantes frequentemente necessitam de atendimento hospitalar e uma pequena parcela - aproximadamente 5\% - destes seguem para unidades de terapia intensiva em função de deficiência respiratória grave. (OMS, 2020).

Este fato se reflete na condição de transmissão comunitária instalada nacionalmente no Brasil, onde mesmo considerando a baixa testagem do país e a constante revisão dos óbitos pela COVID-19 a taxa média de letalidade gira em torno dos $6 \%$ e a projeção de casos chega-se ao mês de maio, provavelmente, na casa dos seis dígitos, espalhados majoritariamente na região Sudeste. Neste sentido, a situação da região Norte é de considerável incidência; em fins de abril, eram $12 \%$ aproximados dos casos nacionais em números absolutos, o que se torna ainda mais dramático considerando a proporcionalidade demográfica entre as cinco macrorregiões nacionais (BATISTA et al, 2020b). 
Na metade de maio, tanto a incidência quanto a mortalidade por 100 mil habitantes na região Norte $(245,7)$ eram o dobro dos índices das mais avançadas regiões neste mesmo retrato conforme dados na tabela 1 (OMS, 2020a).

Tabela 1 Síntese de casos, óbitos, incidência e mortalidade de covid-19 Brasil e regiões.

\begin{tabular}{ccccc}
\hline & Casos & Óbitos & $\begin{array}{c}\text { Incidência } \\
(\mathbf{1 0 0} \text { mil } \\
\text { hab })\end{array}$ & $\begin{array}{c}\text { Mortalidade } \\
(\mathbf{1 0 0} \text { mil } \\
\text { hab })\end{array}$ \\
\hline Região Sudeste & 10.797 & 349 & 36 & 1,2 \\
Região Sudeste & 96.938 & 7938 & 108,6 & 9 \\
Região Centro-Oeste & 7.531 & 171 & 4602 & 1 \\
Região Nordeste & 81.537 & 4.673 & 142,9 & 8,2 \\
Região Norte & 45.277 & 2.987 & 245,7 & 16,2 \\
\hline Brasil & 242.080 & 16.118 & 114,7 & 7,7 \\
\hline
\end{tabular}

Fonte: Ministério da Saúde (2020).

No caso amapaense, como pode ser visto na tabela 2, neste mesmo período valores apresentados acompanhavam a tendência de alta, com média semelhante à regional sobre mortalidade (14,1 do AP x 16,2 do Norte), mas com números alarmantes no que diz respeito à incidência de casos (467,3 do AP x 245,7 do Norte). Desta forma, notase urgente atenção específica à visível contradição entre os padrões de incidência e mortalidade na região à luz da realidade nacional, visto que, considerando a densidade demográfica da região Norte e a quantidade de casos per capita, 5 cidades do Norte estiveram entre as 20 cidades com maior mortalidade em fins de Abril (BATISTA et al, 2020b). 
Tabela 2 Síntese de casos, óbitos, incidência e mortalidade de covid-19 Região Norte e Estados

\begin{tabular}{ccccc}
\hline Estados & Casos & Óbitos & $\begin{array}{c}\text { Incidência } \\
(100 \mathrm{mil} \\
\text { hab })\end{array}$ & $\begin{array}{c}\text { Mortalidade } \\
(100 \mathrm{mil} \\
\text { hab })\end{array}$ \\
\hline AP & 3.952 & 119 & 467,3 & 14,1 \\
RO & 1.963 & 74 & 110,5 & 4,2 \\
AC & 1.997 & 60 & 226,4 & 6,8 \\
PA & 13.864 & 1.239 & 161,2 & 14,4 \\
RR & 1.791 & 51 & 295,7 & 8,4 \\
\hline AM & 1.382 & 31 & 87,9 & 2 \\
\hline Norte & 45.277 & 2.987 & 245,7 & 16,2 \\
\hline
\end{tabular}

Fonte: Ministério da Saúde (2020).

Dada a configuração dos sistemas nacional e regional de saúde pública, são diversos os fatores que, por sua vez tipicamente atrelados a países em desenvolvimento como o Brasil - como baixa quantidade de leitos com respiradores ou capacidade de tratamento intensivo, atraso tecnológico influenciando a qualidade das testagens, ausência de equipamentos de proteção individual (EPI), deficiências nos sistemas sanitários das cidades, saturação da quantidade de pessoas por dormitório em habitações em regiões com altíssima densidade demográfica e a inexperiência brasileira com situações de confinamento e/ou restrição de tráfego - tornam ainda mais incertas as projeções epidemiológicas e infectológicas sobre a COVID-19. Tais incertezas devem observar, ainda que com o devido cuidado, modelagens 
macroscópicas visando a mais aproximada projeção possível 01 (PIRES; CARVALHO; XAVIER, 2020).

\section{A COVID-19 NO AMAPÁ E REGIÃO METROPOLITANA DO ESTADO}

Com chegada do Coronavírus no Amapá em 25.de março.2020 cuja, região metropolitana composta por uma população segundo o IBGE de aproximadamente 845.000 habitantes, distribuídos por 16 municípios com uma taxa de crescimento populacional de $2,02 \%$ (IBGE, 2020).

Torna-se importante para ter um quadro o mais acurado o possível, neste sentido, observar-se padrões comportamentais de circulação de pessoas, de higiene e cuidados com a saúde hospitalar podem influenciar o quadro de propagação da COVID-19 no Amapá, considerando também os padrões de comportamento dos valores absolutos de casos notificados (SVS, 2020).

Tangenciado por uma propagação desenfreada do novo coronavírus no Amapá pensemos em famílias alienadas a força do trabalho e em isolamento social impedidas de desempenhar sua profissão. Nessas condições a única solução é esperar o mal passar, ocasionando outros problemas como ansiedade, depressão, estresse póstraumáticos irritabilidade entre outros impactos psicológicos da quarentena. Para sua resposta dada aos impactos negativos, pessoas sofreram ainda acrescidos de fatos preditivos como: medo, tristeza, culpa confusão, por não conseguir por si só achar uma solução de trabalho ou passatempo. Parte desses contextos psicológicos citado é perceptível em todas as classes e níveis sociais do Estado do Amapá, começando principalmente com profissionais da área de saúde que trabalham e estão sempre em linha de frente dos centros de atendimento que se apresentam inadequado e insuficiente por anos vivido atrás de um sistema político alarmante de desigualdade democrática (BROOKS, 2020).

$\mathrm{Na}$ catalogação existente nos diversos níveis de grupos sociais urbanas e periféricas do estado Amapá, cidade como Macapá e Santana são os dois municípios onde a doença está mais concentrada. Segundo a Superintendência de Vigilância em Saúde 
SVS, essa afirmação pesquisada baseou no período de 14 a 27 de abril, mostrando sempre características concentradoras do COVID-19 no centro da cidade de Macapá, onde tudo começou, isso se deve a pessoas que viajaram para fora do estado e retornaram. Conclui-se que então o efeito da expansão da contaminação é dado por pessoas importadas que chamaremos de Classe A e B (Critério de Classificação socioeconômica). Oposto parcialmente as confirmações do epicentro sub pressionado da COVID-19 no centro de Macapá, está Santana que ratifica sua estatística de concentração em todas as áreas urbanas e periféricas possíveis de deslocamento intermunicipal necessário por motivos familiares, residenciais ou não (contato direto), mesmo com as medidas de contenção aplicada por barreiras sanitárias. Esse panorama será apresentado pelo grupo de pessoas de Classe C, D, E, enquadrados na dependência em uso de transportes coletivos e particulares (SVS,2020).

Nesta ideia comentada acima, integramos um modelo de quadro para as relações de classes ou grupos sociais de isolamento, medida por renda e bem-estar entre os amapaenses (IN LOCO, 2020).

Tabela 3 Relação comparada de isolamento social por grupo socioeconômico.

\begin{tabular}{|c|c|c|c|}
\hline $\begin{array}{c}\text { Grupos Sociais por } \\
\text { Classe }\end{array}$ & Isolamento Social & Bem Estar Social & Cidade \\
\hline$A \in B$ & $\begin{array}{l}40 \% \text { em casa } \\
\text { respeitando o } \\
\text { decreto }\end{array}$ & $\begin{array}{l}\text { Variante conforme o } \\
\text { comportamento da } \\
\text { equidade do início da } \\
\text { pandemia }\end{array}$ & Macapá \\
\hline C, DeE & $\begin{array}{c}60 \% \text { não respeitando } \\
\text { o decreto de } \\
\text { isolamento social }\end{array}$ & $\begin{array}{l}\text { Invariante conforme } \\
\text { até um ponto } \\
\text { convergente das } \\
\text { informações de } \\
\text { prevenção dada do } \\
\text { início da pandemia }\end{array}$ & $\begin{array}{c}\text { Macapá, Santana e } \\
\text { demais Municípios } \\
\text { do Estado }\end{array}$ \\
\hline
\end{tabular}


O cenário em tabela é apenas uma pequena demonstração da realidade social comportamental da população amapaense, sobre valor quanto sua responsabilidade de manter seu bem estar a partir do comprimento em decreto estabelecido pelos órgãos governamentais do Estado. Acalentados em casa pelas notícias seriadas pela pandemia, quadro mostra $40 \%$ das classes $A$ e $B$ se dispondo em cumprir isolamento, parte desse cumprimento é devido essas pessoas possuírem empresas, empregos e salários fixos de Servidor Público em carreira. Contrário das demais classes sociais restantes $\mathrm{C}, \mathrm{D}$ e E fica critério do padrão salarial combinado entre partes contribuintes da renda fixa familiar (dependência Financeira), e trabalhos temporários formais e informais para o bem estar esperado, desconsiderando ser ou não um servidor público de carreira ou formação acadêmica. Este é o motivo do crescente descumprimento do isolamento social, que chega a $60 \%$ com tendência de crescer ainda mais durante os meses correntes (IBGE-AMAPÁ, 2020).

Seguindo a validação dos fatos em assunto a partir de cada classe social intervinda de razões pluralista, traça-se a figura 1 demonstrativo geral apresentando o índice de irresponsabilidade da população quanto isolamento social no Estado do Amapá Cidade de Macapá Capital e demais Municípios no período de 30 de Janeiro a 14 de maio de 2020 com tendência de variar, fracionar ou regredir (IN LOCO, 2020).

Figura 1 Índice de isolamento social para o Amapá no período de 30 de janeiro à 14 de maio

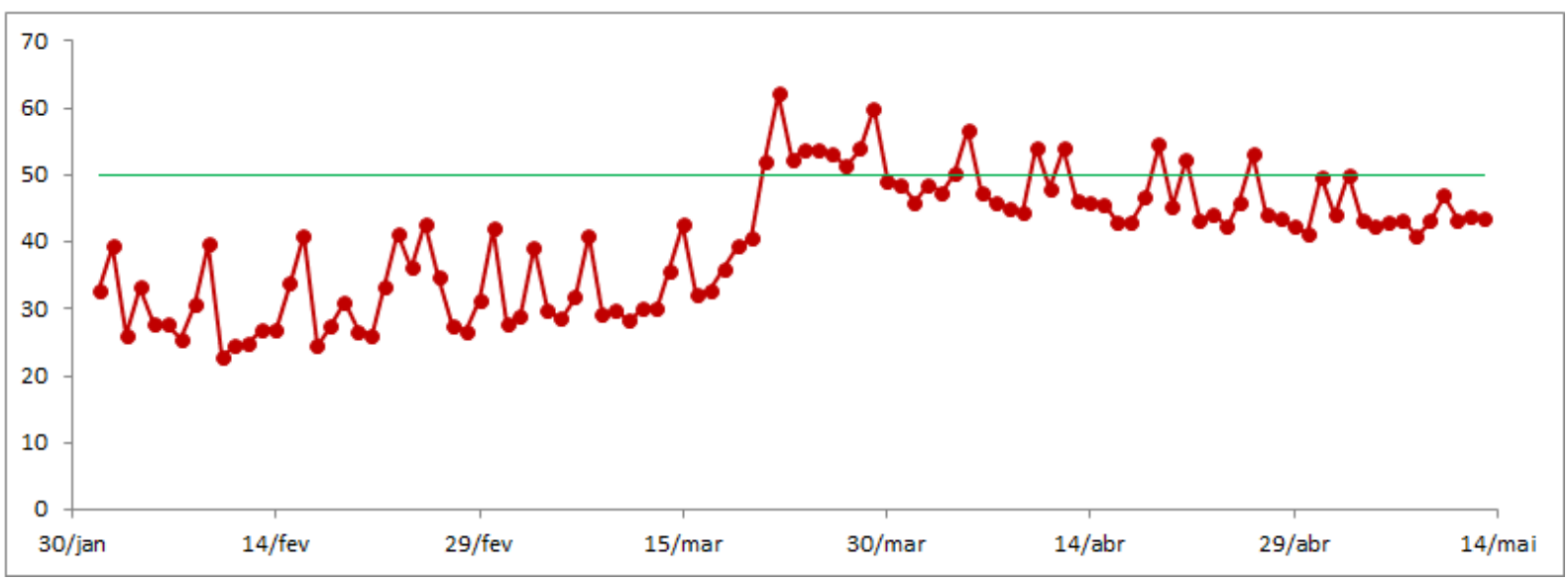

Fonte: In Loco (2020) 
Análises estatísticas de isolamento social, ainda são variantes incertas para o acordado em prática pela população amapaense, ainda se espera do período em gráfico até o dia 14 de maio de 2020 a variação, considerado do cumprimento de ficar em casa e sair apenas se necessário ou emergência. Ações de barreiras fiscalizadora sanitárias serão, a base do controle do fluxo intenso de pessoas ao redor da cidade. E mesmo havendo bastantes casos sintomáticos suspeitos do vírus assim informado, continua-se monitorando o esperado resultado incontrolável. (SVS, 2020)

\section{OBJETIVO}

Esta pesquisa tem por objetivo analisar a incidência de casos confirmados de COVID19 no Amapá/AP com o uso de métodos estatísticos e modelos matemáticos com a finalidade de entender a dinâmica de contágio do vírus, proporcionando informações para promover estratégia de combate mais efetivas contra o covid-19.

Entre outras especificações impulsionadoras, pretende-se, verificar o comportamento forçado da restrição social no ambiente público e doméstico dado como uma das condições de cuidados prioritários para redução prolifera de contágio pelo Coronavírus.

\section{METODOLOGIA}

Em geral duas abordagens de modelagem têm se empregado para se obter insights sobre a evolução epidêmica relacionada ao Sars-CoV-2. Por um lado, há uma empreitada para desenvolver modelos sofisticados que levem em conta diversas variáveis que possam descrever a dinâmica epidêmica. Tal abordagem foi empregada, por exemplo, em Zhang (2020) com um sistema de 15 equações diferenciais. Por outro lado, também tem se adotado uma visão matemática focando nas principais características epidêmicas do processo de contágio com êxito para a curva epidêmica do coronavírus através de versões primárias ou estendidas dos modelos SIR (TODA, 2020; KATUL, 2020; ZHONG, 2020). 
O Modelo epidemiológico SIR proposto por Kermack e McKendrick em 1927 (HETHCOTE, 2000) é um dos modelos clássicos utilizado para a descrição da evolução do processo de contágio de doenças infecciosas. Este modelo composto por equações diferenciais emprega a estratégia de compartimentos e divide, em relação a doença, a população em indivíduos que podem contrair, indivíduos que podem transmitir e indivíduos que se recuperaram e não estão sujeitos a nova contaminação denominados suscetíveis $(S)$, infectados (I) e recuperados $(R)$ respectivamente.

Matematicamente, um modelo SIR pode ser representado usando as seguintes equações diferenciais:

$$
\begin{aligned}
& \frac{d S}{d t}=-\frac{\beta I S}{N}, \\
& \frac{d I}{d t}=\frac{\beta I S}{N}-\gamma I, \\
& \frac{d R}{d t}=\gamma I,
\end{aligned}
$$

Onde $\beta$ é a taxa de transmissão da doença, $\gamma$ é a taxa de recuperação dos indivíduos, ambos são parâmetros positivos e característicos dos dados em análise.

Visando otimizar e estimar estes parâmetros para que os casos relatados e simulados sejam aproximadamente iguais, são usados valores iniciais para as variáveis de três estados $S(0), I(0)$ e $R(0)$.

O valor inicial $S(0)$ é a comunidade população afetada pelo surto, enquanto, $I(0)$ é o número de casos confirmados que podem ter qualquer valor, mas não zero. Podemos definir $R(0)$ a zero se os horários de início do spread e simulação são iguais. A taxa de transmissão reduz monotonicamente com o tempo (HARKO, 2014). 
Resolvendo o sistema (1) determinamos a função solução para a população de suscetíveis e obtemos (BATISTA, 2020).

$$
S=S_{0} \exp \left[-\frac{\beta}{N \gamma}\left(R-R_{0}\right)\right]
$$

Dentre os parâmetros relevantes usados em modelos epidemiológicos como o SIR está a reprodutibilidade basal que é fornecida por $R_{0}$ (conhecida como taxa de reprodução) definida por $R_{0}=\beta / \gamma$. A taxa $R_{0}$ é afetada, dentre vários fatores, pelo número de pessoas suscetíveis na população com as quais os pacientes afetados estão em contato podendo ser descrita como o número médio de pessoas que são infectadas por um único indivíduo (DELAMATER et al, 2019).

Segundo Ghani e Fergunson (2020), o valor de $R_{0}$ para o COVID-19 tem variado entre 1 e 7 (mais precisamente 1.1 a 6.95) ao longo do desenvolvimento da epidemia. Conforme indicado por Delamater et al (2019), um $R_{0}<1$ demonstra que o número de infectados decresce com o tempo e a epidemia tende a se erradicar, para valores de $R_{0}>1$ tem-se que a epidemia deve persistir na população por um longo prazo.

Assim, tomando o limite quando $t$ tende ao infinito, o número de pessoas suscetíveis obtidos é:

$$
S_{\infty}=S_{0} \exp \left[-\frac{\beta}{N \gamma}\left(R_{\infty}-R_{0}\right)\right]
$$

Onde é a quantidade final de recuperados. Considerando que a quantidade final de infectados seja zero, tem-se:

$$
N=S_{\infty}+R_{\infty}
$$


De (03) obtemos

$$
R_{\infty}=N-S_{0} \exp \left[-\frac{\beta}{N \gamma}\left(R_{\infty}-R_{0}\right)\right]
$$

Assumindo que os dados disponíveis são uma série temporal do número total de casos $C=R+I$, os parâmetros e os valores iniciais são definidos pela minimização da diferença entre os valores atuais e os números de casos calculados:

$$
\left\|C_{t}-\hat{C}_{t}\left(\beta, \gamma, S_{0}\right)\right\|^{2}=\min
$$

onde $C_{t}=\left(C_{1}, C_{2}, \ldots, C_{n}\right)$ é o número de casos no instante $t=1,2, \ldots, n$ e 0 vetor corresponde aos valores estimados nos mesmos instantes de tempo dos valores informados. A minimização em questão foi obtida pela função fminsearch do MATLAB conforme Batista (2020).

Ressaltamos que na abordagem supracitada há três parâmetros a serem estimados, nomeadamente $\{\beta, \gamma, N\}$ onde $N$ é o tamanho efetivo da população. Denotamos tal variante pela sigla vSIR para diferenciar do modelo SIR padrão onde $N$ é o tamanho total da população que é uma quantidade definida a priori. Computacionalmente, a solução numérica do sistema de equações vSIR é implementada com o software MATLAB empregando-se o método explícito de Runge-Kutta de quarta ordem (BATISTA, 2020).

Todas as análises com o modelo matemático deste estudo foram realizadas com os dados de casos confirmados de covid-19 para o Estado do Amapá, disponibilizados pela Secretaria Estadual de Saúde do Estado e o Ministério da Saúde do Brasil, ambos online, tratando-se de dados secundários, por esta razão, foi dispensável o registro da pesquisa em comitê de ética. 


\section{RESULTADOS E DISCUSSÕES}

\section{ANÁLISE DE PROJEÇÃO DO}

\section{MODELO IMPERIAL COLLEGE LONDRES}

Apresentamos neste tópico algumas projeções locais realizadas com o modelo do Imperial College de Londres (ICL), que buscou guiar políticas públicas emergenciais no controle epidemiológico-infectológico da COVID-19 para países afetados, obviamente todos os modelos carecem de adequação atenta em momento imediato à expansão transoceânica da pandemia, considerando os fatores agravantes que ocorrem em cada região.

Assim, o 'Modelo ICL' descreve da seguinte maneira os cinco cenários:

A) Uma epidemia não mitigada - um cenário em que nenhuma ação é tomada.

B) Mitigação, incluindo distanciamento social em nível populacional - avaliamos a redução máxima na escala final da epidemia que pode ser alcançada por meio de uma redução uniforme na taxa em que os indivíduos se comunicam, com exceção da supressão completa.

C) Mitigação, incluindo maior distanciamento social dos idosos - como (B), mas com indivíduos com 70 anos ou mais, reduzindo suas taxas de contato social em $60 \%$.

D e E) Supressão - exploramos diferentes gatilhos epidemiológicos (mortes por 100.000 habitantes) para a implementação de distanciamento social intensivo em larga escala (modelado como uma redução de $75 \%$ nas taxas de contato interpessoal) com o objetivo de suprimir rapidamente a transmissão e minimizar casos a curto prazo e mortes.

Para esses cenários, não produzimos estimativas de tamanho final, mas ilustramos seu impacto em configurações representativas. Para Tardia, considera-se realização de testes em massa, isolamento dos casos positivos e monitoramento de pessoas 
próximas aos diagnosticados a partir de 1,6 morte por 100 mil habitantes por semana. Para Precoce, as mesmas medidas anteriores, mas adotadas a partir de 0,2 morte por 100 mil habitantes por semana (GHANI; FERGUSON, 2020).

Os cenários expostos pelo ICL para uma população do Brasil de mais de 200 milhões de pessoas no presente momento, são extrapolados (em função da premissa fundamental da minimização de impactos para a população) são os seguintes: Cenário A - Sem medidas de mitigação; Cenário B - Com distanciamento social de toda a população. No Cenário $\mathrm{A}$, o quadro brasileiro é temerário, e a depender do cenário, com percentuais de infectados variando de $88 \%$ e baixando até $5 \%$ da população, para o número de mortes variando entre $1 \%$ a $0,02 \%$. Há, ainda, um terceiro Cenário - o C - que trabalha com distanciamento social e reforço do distanciamento dos idosos. Por fim, consideram-se os cenários $D$ e $E$, correspondentes à supressão tardia e precoce, respectivamente, sendo dentre os cenários catastróficos, os de menor destruição quantitativa, como pode ser observado abaixo.

Construímos, à guisa de apreciação, a seguinte projeção nacional, segundo o Modelo ICL.

Tabela 4 Projeções para o Brasil segundo o modelo do ICL

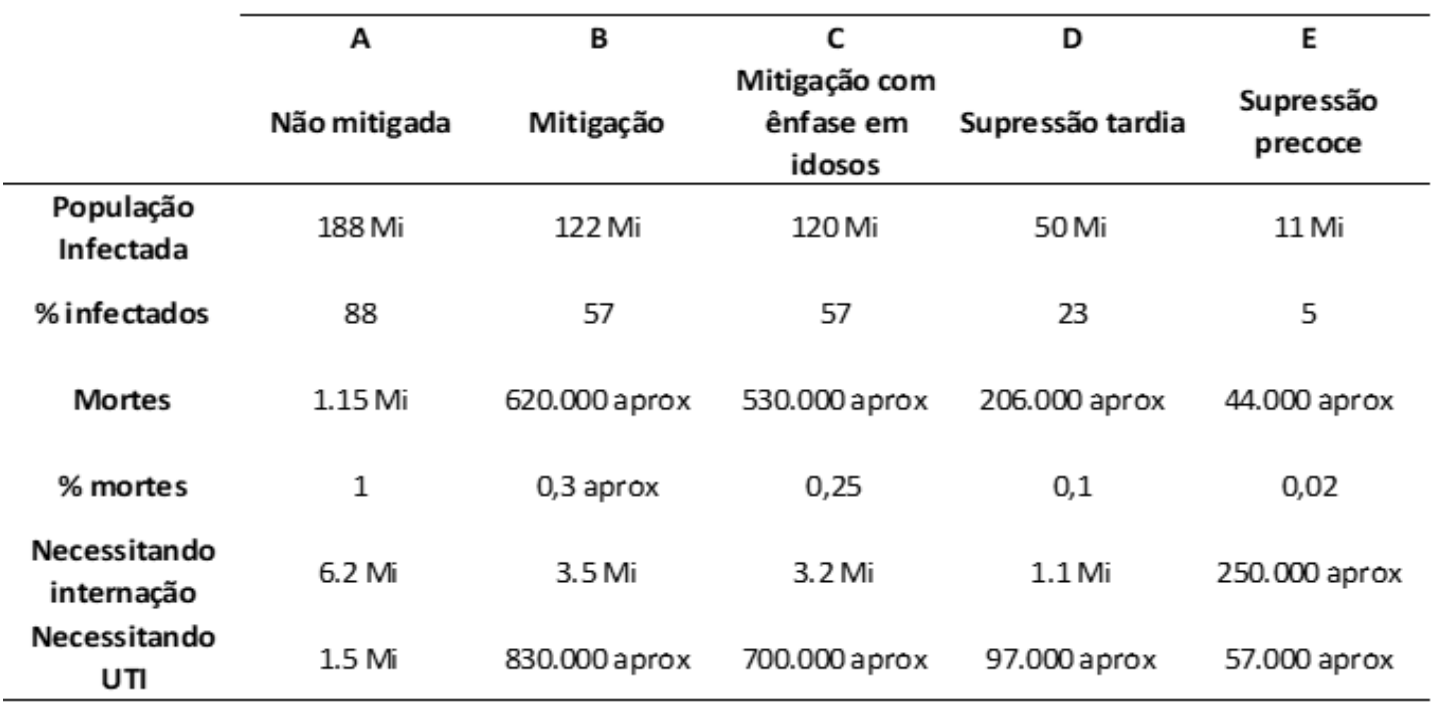

Fonte: Produzida pelos autores com dados da pesquisa. 
Em fins de março, o cenário corrente apontava para uma aceleração do número de casos detectados, aproximadamente uma semana depois das tensões em torno do confinamento, como pode ser visto na projeção a seguir. Os dados do Ministério da Saúde, consolidando as Secretarias Estaduais de Saúde, apontam 5.812 infectados e 202 mortes no 36ํㅡ Dia após o Primeiro Caso Confirmado. Foram 22 dias até o $500^{\circ}$ caso, e daí aos $1000^{\circ}$ foram necessários apenas 2 dias, dobrando em três dias (2000) e chegando ao dobro dos 2000 em 5 dias. Nos últimos 15 dias de março, portanto, houve uma franca aceleração (PRADO, M. et al., 2020).

Já é reconhecido que o Brasil vivencia desde o princípio da pandemia um cenário de subnotificação, com uma taxa de notificação no Amapá estimada em cerca 11,2\%, conforme apontado em estudo na primeira quinzena de abril (PRADO et al., 2020). Pode-se observar este fator em função dos problemas de planejamento para o 'estouro' da crise - apesar desta já estar prevista desde a última semana de janeiro, quando a proliferação começou a superar o continente asiático - e da baixa quantidade de testes, que por sua vez estão sendo em sua maioria aplicados em indivíduos sintomáticos, desconsiderando o enorme potencial de contaminados assintomáticos; isso é, que já foram infectados pelo vírus, mas não tendo sintomas, sentem-se confortáveis para o livre tráfego e potencializam a transmissão. Devem ser pesados ainda, de forma a tornar o caso brasileiro específico, fatores como as tensões desde fins de março em torno de parte significativa da população que contesta o confinamento ou minimizar seus efeitos, configurando peso ao caráter elástico e informal das promoções de livre circulação anteriores (PRADO et al., 2020).

No caso amapaense, em março já era observada a possível escalada, ainda que mantida naquela progressão corrente, para os casos nativos - já em transmissão comunitária (AMAPA, 2020a)- em função dos contratempos com a autorização para os testes locais (autorizada apenas em 27/03 - e com a redução do tempo de progressão desde 26/3. Com relação ao mês de março, entre 19 e 24/3, registramos 1 caso durante 5 dias; entre 25 a 26/3, passamos ao $2^{\circ}$ caso; entre 27 e 28/3, passamos ao 3o; no dia 29/3, 6 casos; em 30/3, 8 casos; e em, 31/03, 10 casos. Em 
abril, o ritmo observado de casos cresceu em risco de descontrole ambiental (AMAPÁ, 2020a)

Considerando ainda que as últimas projeções do IBGE trate de uma população de 845.000 pessoas estimadas para o Amapá (IBGE, 2020), caso se projete a modelagem do ICL para o estado, de forma linear comparada ao cenário nacional - o que por si só já representa mais um fator para a distorção - teríamos o seguinte cenário de predição, severamente extrapolado a ser acumulado ao longo de todo o primeiro ciclo epidemiológico de propagação da COVID-19 a seguir:

Tabela 5 Projeção comparada linear do modelo ICL p. COVID-19 aplicado ao Brasil para o Amapá

\begin{tabular}{|c|c|c|c|c|c|}
\hline & $\begin{array}{c}\text { A } \\
\text { Năo mitigada }\end{array}$ & Mitigaçăo & $\begin{array}{c}\text { C } \\
\text { Mitigaçăo com } \\
\text { ênfase em } \\
\text { idosos }\end{array}$ & $\begin{array}{c}\text { D } \\
\text { Supressão tardia }\end{array}$ & $\begin{array}{c}\text { E } \\
\text { Supressão } \\
\text { precoce }\end{array}$ \\
\hline $\begin{array}{l}\text { Populaçăo } \\
\text { Infectada }\end{array}$ & 743.000 aprox & 480.000 aprox & 480.000 aprox & 194.000 aprox & 42.000 aprox \\
\hline$\%$ infectados & 88 & 57 & 57 & 23 & 5 \\
\hline Mortes & 8.400 aprox & 2.500 aprox & 2.100 aprox & 845 & 160 \\
\hline$\%$ mortes & 1 & 0,3 & 0,25 & 0,1 & 0,02 \\
\hline $\begin{array}{l}\text { Necessitando } \\
\text { internaçăo }\end{array}$ & 22.000 aprox & 12.000 aprox & 11.000 aprox & 3.600 aprox & 1500 aprox \\
\hline
\end{tabular}

Fonte: Produzida pelos autores com dados da pesquisa.

Em função do Decreto do Governo do Estado do Amapá (GEA) № 1414/2020, que promoveu ampla redução de atividades econômicas, sociais e culturais, e da ampla adoção de ações em favor da desconcentração de pessoas, o cenário A está iminentemente descartado no seu extrapolar na medida em que se mantiver o isolamento. A preocupação fundamental passa a ser, de forma cogente, a 
manutenção do isolamento com medidas de contenção inteligente de fluxos para evitar a indisciplina social com relação a este, para mitigar ao máximo os padrões do cenário $B$ e $C$ para aproximarmo-nos do realístico cenário $D$, de supressão tardia - o que tornaria, em números absolutos, a crise navegável no Amapá, dada a sua densidade demográfica e seu contingente populacional. A razão para otimismo se dá em favor das ações rápidas das prefeituras metropolitanas e principalmente do governo do estado; contudo, as condições técnicas de notificação, bem como o quantitativo e qualitativo das instalações e leitos de internação ou tratamento intensivo sugerem emergência quando se eventualmente confirmar uma proliferação de casos. Por isso, conter a transmissão comunitária foi constatada como a melhor opção. As previsões apresentadas em projeção de equipe conjunta da Fundação Getúlio Vargas e da Fundação Oswaldo Cruz (FGV/Fiocruz) apontam convergentemente para efeitos positivos das restrições sociais e de translado combinadas no que diz respeito a uma próxima onda nacional acumulado ao longo de todo o primeiro ciclo epidemiológico de propagação da COVID-19 (ZORZETTO, 2020).

É importante reiterar a preocupação com as óbvias adequações da modelagem ICL com relação às características socioculturais e socioeconômicas do nosso país. Ao mesmo passo, os dados dos cenários da modelagem ICL são números extrapolado e podem, nesse sentido, constituírem exagero. Neste sentido, de forma preventiva, verificando a propensão para os próximos dias de multiplicação de casos nacionais e a ainda corrente implantação do sistema local de testagens e a iminente chegada de exames de testagem rápida - que provavelmente serão hipossuficientes e serão focados em população sintomática, o que retarda o aperfeiçoamento de qualquer projeção em função do período de incubação imediato ao contágio e, portanto, turva a percepção real do quadro epidemiológico - considera-se provável que a transição de um Cenário D para $C$ seja possível. Em caso dessa transição se confirme, serão inevitáveis perspectivas de securitização da cidade por zoneamento de trânsito de pessoas e mercadorias (modelo Wuhan de confinamento reforçado por restrição ao trânsito intrazonal) para atingir o percentual desejável 60\%-75\% de restrição, notando ainda que mapeamentos de casos por região seriam positivamente determinantes ajudar a conter de forma mais precisa a transmissão comunitária e observar tanto 
contaminados quanto idosos. A antecedência e massificação de testes, distanciamento social, priorização da localização de idosos e co-mórbidos, bem como o isolamento dos diagnosticados, são decisivos neste sentido (ZORZETTO, 2020).

\section{MODELAGEM VSIR PARA AVALIAÇÃO DA CURVA DE CASOS ACUMULADOS DE COVID-19 NO AMAPÁ}

A série temporal com os casos confirmados de covid-19 para o Estado do Amapá pertence ao recorte de 25 de março à 12 de maio. Neste período, o referido Estado apresentava a seguinte evolução de indivíduos testados positivos, mortalidade e recuperados:

Figura 2 Casos confirmados de covid-19 (A). Evolução da mortalidade (B). Casos recuperados $(\mathrm{C})$.

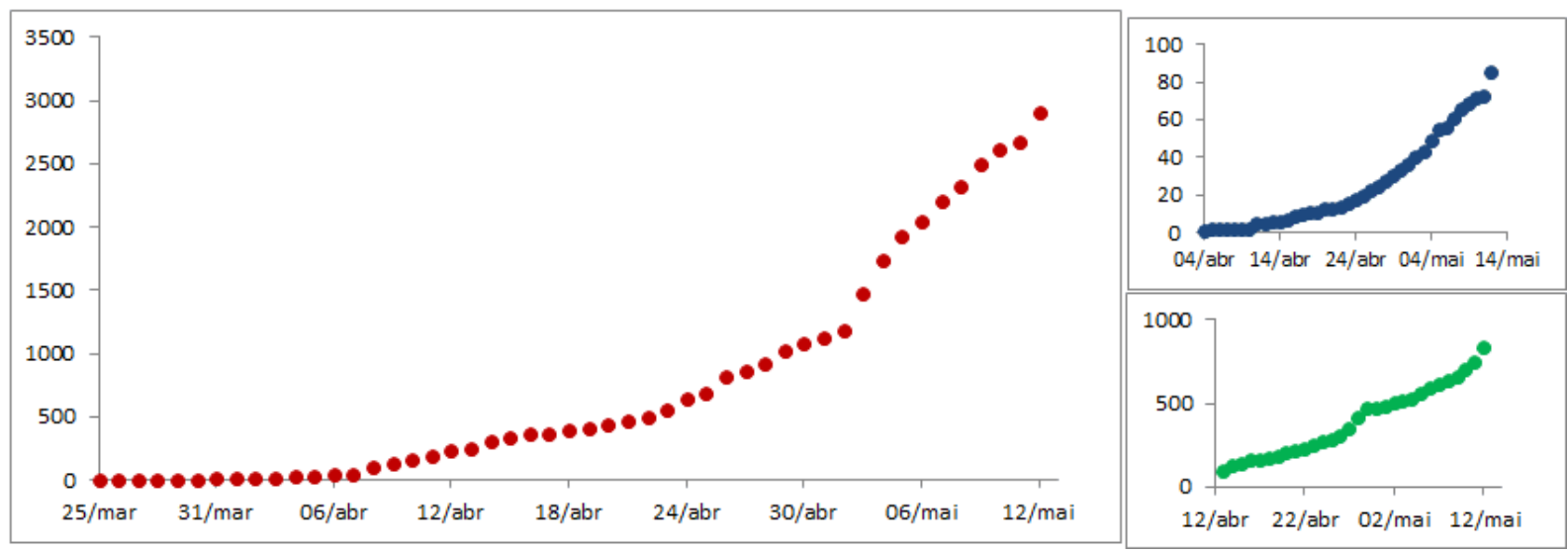

Conforme se verifica na figura 2, em (A), o Amapá levou 50 dias para sair de 1 caso para 2910 (25/03 a 12/05). Nesta data de fechamento do estudo, o estado detinha uma das maiores taxas relativas de casos com cerca de 355.3 por 100 mil habitantes, chamando atenção do país inteiro em razão de ser um estado com menos de 1 milhão de habitantes.

Com base neste cenário, no início da evolução temporal epidêmica para o Amapá, podemos assumir $S \cong N$. Assim, a equação para $d l / d t$ no sistema (1) torna-se: 


$$
\frac{d I}{d t} \cong(\beta-\gamma) I=\gamma\left(R_{0}-1\right) I
$$

Onde $R_{0}=\beta / Y .$. Após uma integração direta obtemos

$$
I(t) \cong I_{0} e^{\left(R_{0}-1\right) \gamma t}
$$

Para obter uma primeira estimativa de $R_{0}$ aplicarmos uma linearização da equação acima. Desse modo obtemos $\log (I(t))=m t+\log \left(l_{0}\right)$, onde temos o coeficiente angular $m=\gamma\left(R_{0}-1\right)$. $O$ fit com as ferramentas estatísticas da linguagem de programação $R$ fornece $m=0.21547 \pm 0.01163$. Baseado na literatura (TODA, 2020; LI, 2020; READ, $2020)$ assumimos $y$ no intervalo $[0.1,0.6]$. Com isso temos uma estimativa preliminar de $R_{0}$ entre [1.340, 3.271] que é um intervalo comparável com valores reportados nas tabelas sumárias dos artigos de revisão sobre $R_{0}$ (LIU, 2020; ALIMOHAMADI, 2020).

Com relação à fase de crescimento exponencial dos casos de covid-19, na figura 3 nota-se uma concordância satisfatória entre os dados observados e a previsão teórica (curva vermelha) até o dia 14 de abril. Entretanto, logo a seguir ocorre uma discrepância precoce do fit preliminar com os dados, o que suscita questionamentos sobre o motivo de tal comportamento. Uma possível justificativa para esta alteração na tendência surge da percepção de que o período coincide com o início de políticas públicas para evitar os contágios. Dentre elas, está o Decreto №1497 de 03 de abril de 2020 do Governo do Estado do Amapá que determina de forma imediata o isolamento social e a suspensão de serviços considerado de aglomeração física, acarretando novos horários de funcionamento e mantendo aberto apenas estabelecimento de extrema necessidade. Desta forma, observa-se que as medidas de isolamento têm seu impacto no número de casos, após o retardo de dezesseis dias relacionados ao período de incubação. 
Figura 3 Crescimento exponencial inicial

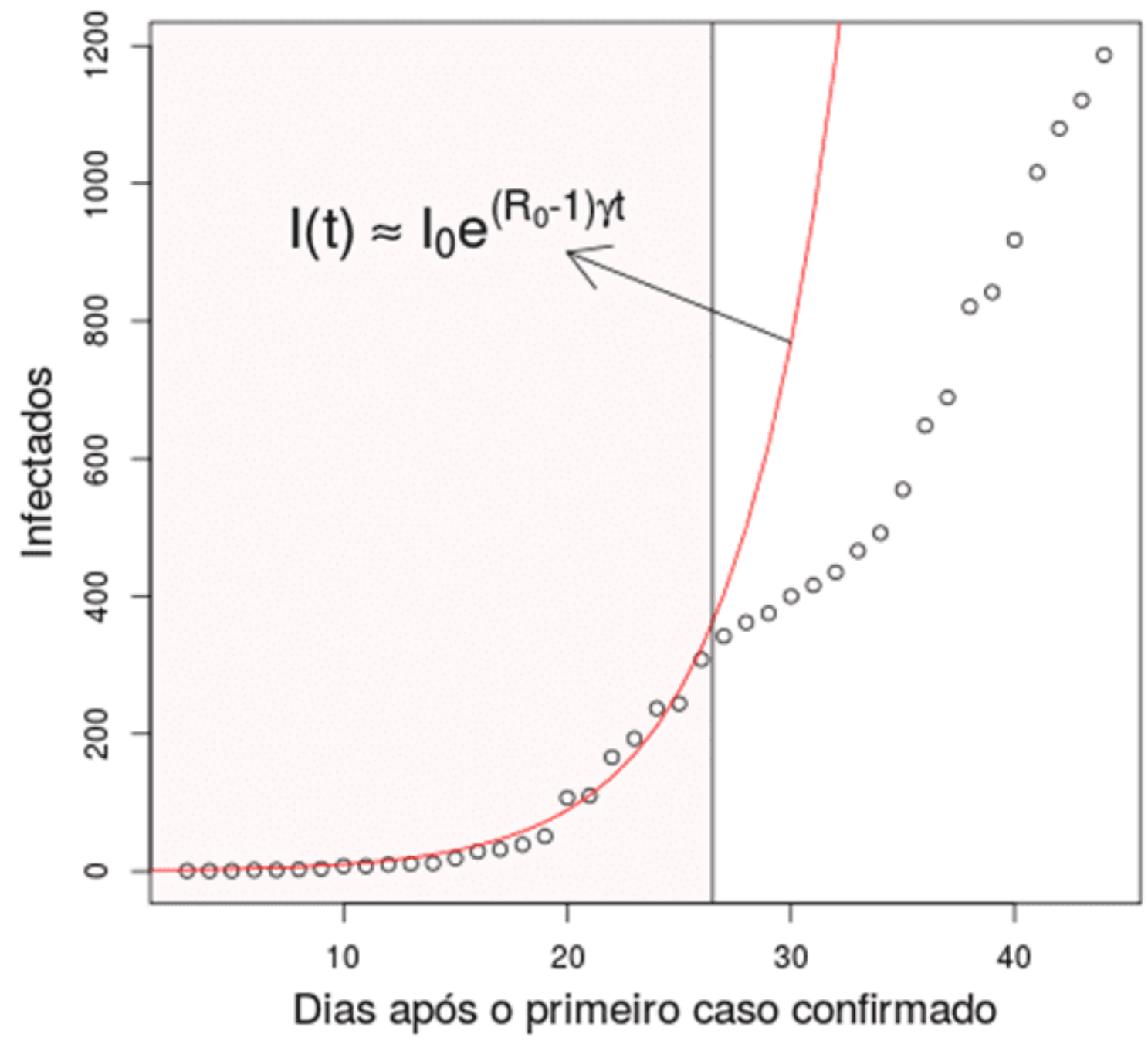

Enquanto a figura 3 apresenta uma análise do curto prazo com o ajuste exponencial (25/3 a 14/04), nas análises posteriores os dados confirmados da epidemia são comparados com o modelo matemático SIR padrão e a variante empregada por Batista (2020) (que chamamos de vSIR, por brevidade). 
Figura 4 Simulação VSIR e intervalo de confiança

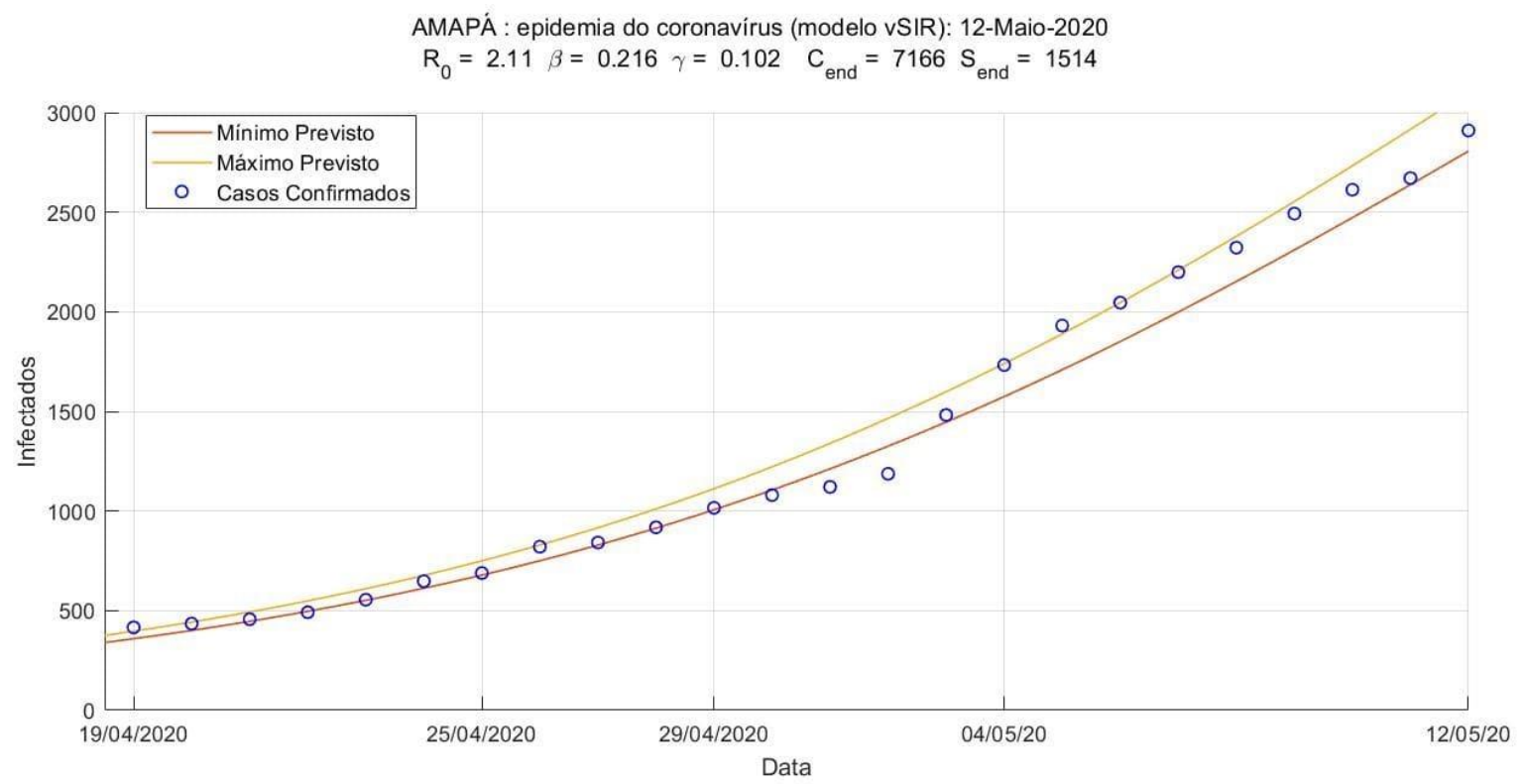

A simulação do modelo vSIR do dia 25.03, até o dia 12.05.2020 exposta na Figura 03 apresenta o intervalo de confiança (IC) que define os limites inferior e superior dos valores simulados de modo a conferir $95 \%$ de probabilidade de incluir o valor real de casos preditivos. Observa-se dois pontos outliers que ocorrem em 01de maio de 2020 e 02 de maio 2020, sexta-feira e no sábado respectivamente. Estas datas que envolvem o feriado nacional do dia do trabalho e cujas quantidade de infectados foge ao esperado suscitam questões envolvendo o método processual de coleta de informações que serão averiguadas posteriormente a partir de uma análise de dados in loco. Destaca-se ainda que modelo foi calibrado com base nos dados reais de infectados desde o início da pandemia no estado. 
Figura 5 Curva de predição dos casos até o dia 31.05.2020

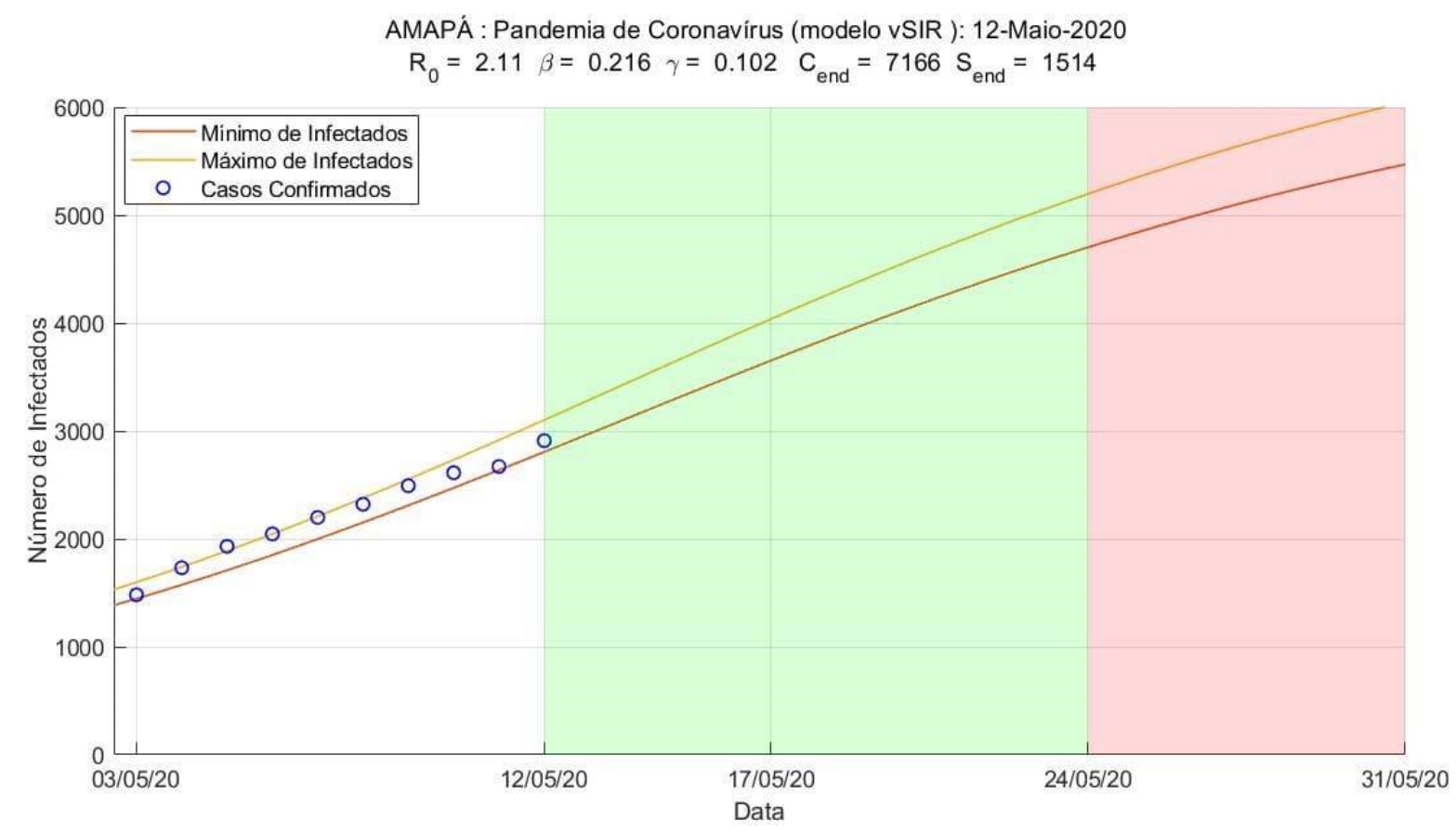

É possível observar na figura 5 a curva de predição dos casos de Covid-19 no estado até o dia 31.05. Verifica-se que, até o dia 17.05 (domingo), o modelo estima que o estado terá o número de casos de infectados próximo dos 4 mil (3651-4036), na semana seguinte no dia 24.05 este número estará próximo dos 5 mil casos (47005196), e por fim até o final do mês de maio, no dia 31.05 esses valores giram em torno dos 5,5 mil casos (5469-6044). o que representa quase o dobro do que foi registrado no dia 12.05. A área em verde que vai do dia 12.05 até o dia 24.05 representam datas em que o modelo têm maior efetividade na predição (datas próximas), já a área vermelha representa as datas em que o modelo pode falhar na predição (BATISTA, 2020).

Os parâmetros estimados para os dados do Amapá, utilizando a programação fminsearch do MATLAB, desenvolvido por Batista (2020), foram os seguintes: 
Tabela 6 Parâmetros estimados no modelo Vsir

\begin{tabular}{ccc}
\hline$R_{0}$ & $\beta$ & $\gamma$ \\
2.11 & 0.216 & 0.102 \\
\hline
\end{tabular}

O valor estimado da taxa básica de reprodução $R_{0}$ está de acordo com os valores reportados pela literatura especializada em revisão sistemática e metadados como em Liu (2020) e AliMohamadi (2020). No gráfico da figura 04 observa-se também um valor = 7166 que é uma projeção para o número de casos para os dias subsequentes aos dados disponíveis. Apesar do nome, não se refere ao número final previsto se os dados disponíveis ainda estiverem nos estágios iniciais e intermediários da evolução epidêmica, como é justamente a situação presente dos dados no AP. Como veremos a seguir o modelo vSIR fornece previsões de 5-10 dias de em consonância com os dados observados.

$\mathrm{Na}$ tabela 7 , é possível observar os valores previstos de casos, com um IC de $95 \%$. Vale ressaltar que esses valores são válidos caso não haja mudança nas políticas públicas, ou na atitude individuais significativas, no sentido de medidas mais duras com relação ao isolamento. 
Tabela 7 Predição do número de infectados por dia.

\begin{tabular}{ccc}
\hline Data & $\begin{array}{c}\text { Intervalo de casos previstos } \\
\text { Mínimo }\end{array}$ & Máximo \\
\hline $\mathbf{1 3 . 0 5 . 2 0 2 0}$ & 2975 & 3288 \\
$\mathbf{1 4 . 0 5 . 2 0 2 0}$ & 3146 & 3477 \\
$\mathbf{1 5 . 0 5 . 2 0 2 0}$ & 3316 & 3665 \\
$\mathbf{1 6 . 0 5 . 2 0 2 0}$ & 3485 & 3852 \\
$\mathbf{1 7 . 0 5 . 2 0 2 0}$ & 3651 & 4036 \\
$\mathbf{1 8 . 0 5 . 2 0 2 0}$ & 3815 & 4216 \\
$\mathbf{1 9 . 0 5 . 2 0 2 0}$ & 3975 & 4394 \\
$\mathbf{2 0 . 0 5 . 2 0 2 0}$ & 4130 & 4565 \\
$\mathbf{2 1 . 0 5 . 2 0 2 0}$ & 4281 & 4732 \\
$\mathbf{2 2 . 0 5 . 2 0 2 0}$ & 4427 & 4893 \\
$\mathbf{2 3 . 0 5 . 2 0 2 0}$ & 4567 & 5048 \\
$\mathbf{2 4 . 0 5 . 2 0 2 0}$ & 4700 & 5196 \\
$\mathbf{2 5 . 0 5 . 2 0 2 0}$ & 4829 & 5338 \\
$\mathbf{2 6 . 0 5 . 2 0 2 0}$ & 4951 & 5472 \\
$\mathbf{2 7 . 0 5 . 2 0 2 0}$ & 5055 & 5600 \\
$\mathbf{2 8 . 0 5 . 2 0 2 0}$ & 5176 & 5721 \\
$\mathbf{2 9 . 0 5 . 2 0 2 0}$ & 5280 & 5835 \\
$\mathbf{3 0 . 0 5 . 2 0 2 0}$ & 5377 & 5944 \\
$\mathbf{3 1 . 0 5 . 2 0 2 0}$ & 5469 & 6044 \\
\hline
\end{tabular}

Fonte: Produzida pelos autores com dados da pesquisa.

Considerando a tabela de previsão de casos acumulados de infectados por covid-19 no Amapá, no dia 31 de maio de 2020, o modelo prevê que o Estado poderá ter entre 5469 a 6044 casos acumulados. Levando-se em conta a atual proporção $p$ de letalidade calculada para esta unidade federativa que no dia 12 (último dia de dados 
reais coletados) seu valor era de $p=2.95 \%$. Mantido este patamar, em 31 de maio poderemos ter entre 161 a 178 óbitos em decorrência da doença.

Com relação ao número básico de reprodução $R_{0}$ o modelo vSIR também gerou uma série temporal para acompanhamento diário da evolução de $\mathrm{O}$ acompanhamento diário de $R_{0}$ objetiva conhecer a magnitude detalhada da evolução da doença, além de ser um indicador das políticas públicas não farmacêuticas para mitigação do COVID-19.

Figura 6 Evolução diária de $R_{0}$.

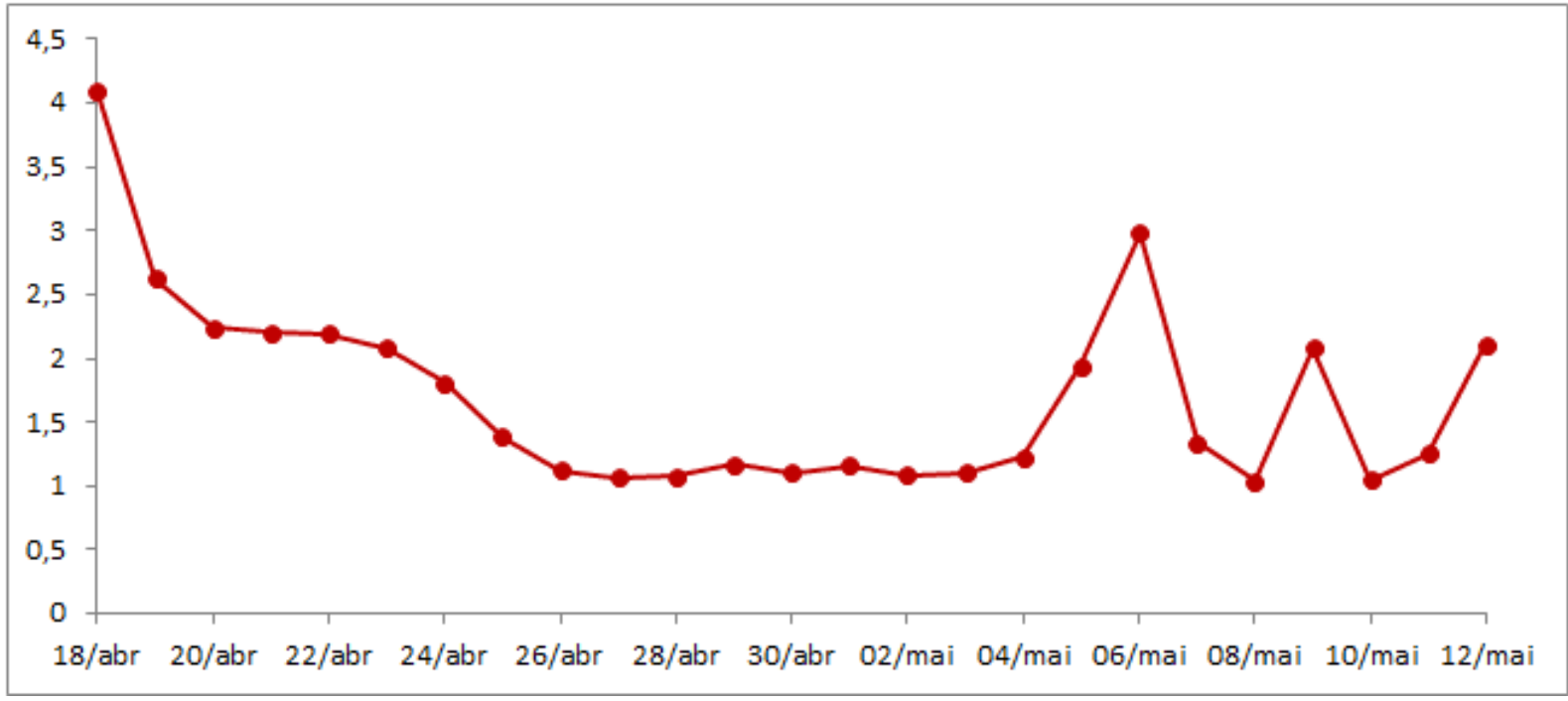

A evolução diária de $R_{0}$ demonstra que os menores valores ocorreram entre 26 de abril $\left(R_{026 / 04}=1.12\right)$ a 03 de maio $\left(R_{003 / 05}=1.1\right)$ esse período de baixo $R_{0}$ pode estar indicando que o decreto governamental de 03 de abril contribuiu para reduzir a taxa básica de reprodução, mas não o suficiente para baixar seu valor para menos de 1 que é o ideal para controle da epidemia. A partir de 03 de maio, $R_{0}$ voltou a subir estando no dia $12 / 5$ no patamar de 2.11, esse aumento pode indicar relaxamento da quarentena pela população, cuja relação com $R_{0}$ é inversa, reduzindo a quarentena, aumenta-se $R_{0}$ e vice-versa, conforme reportado em Dandekar e Barbastathis (2010). 


\section{LIMITAÇÕES DO ESTUDO}

Enquanto que no modelo SIR há apenas dois parâmetros a serem estimados (nomeadamente a taxa de transmissão $\beta$ e recuperação $\gamma$ ), no modelo vSIR temos a possibilidade de estimar um parâmetro adicional que é o tamanho efetivo da população $N$. Com esses três parâmetros $\{\beta, \gamma, N\}$ conseguimos descrever satisfatoriamente as séries temporais para a quantidade de casos confirmados no estado do Amapá.

Nossa modelagem pode ainda ser melhorada em trabalhos futuros considerando-se as seguintes limitações:

- Observa-se a limitação da aplicação linear e geral do Modelo ICL, por um lado, e por outro, devem ser observadas possíveis imprecisões em função da interdependência e complexidade das condições específicas do desenvolvimento humano no Brasil - já citados, como por exemplo concentração demográfica acentuada em dezenas de cidades, condições precárias de saneamento básico em comunidades carentes, habitações com moradores por cômodo acima do recomendado pela Organização Mundial da Saúde (OMS), inexistência histórica de outras experiências de emergência sanitária com medidas deste porte e padrão. Ou seja, o Brasil tem proporção e condições demográficas específicas, o que acirra a imprecisão de modelos gerais.

- A subnotificação de casos de covid-19 é um fator que tem sido reportado recorrentemente pelo mundo, o que no caso brasileiro, em função da reduzida quantidade de testes, faz com que a incidência deste fator seja crítica. Por exemplo, recentemente foi estimado $86 \%$ (Intervalo de confiança de $95 \%$ : 82 $90 \%$ ) de subnotificação nos primeiros estágios da evolução epidêmica quando as restrições de viagem ainda não estavam impostas (LI, 2020). Para o Amapá, há estimativas que projetam um índice de subnotificação de 11,2\%, conforme nota técnica publicada em 11/abril (BATISTA et al, 2020b).

- O modelo vSIR não leva em consideração o número de casos assintomáticos. Por exemplo, no artigo de revisão de (BUITRAGO-GARCIA, 2020) foi estimado 
um limite superior para a proporção de infecções assintomáticas por SARSCoV-2 de 29\% (intervalo de confiança de 95\%: 23-37\%). Uma estratégia para obter uma estimativa da fração de casos assintomáticos no Amapá consiste em investir na testagem de uma proporção massiva da população.

\section{CONCLUSÕES}

Na primeira abordagem desenvolveu-se uma projeção comparada linear do modelo ICL para o COVID-19 aplicado ao Brasil para o Amapá cujas conclusões apontam para a premência de medidas de isolamento social as mais precoces possíveis, considerando a necessidade de evitar-se contágio massivo e acelerado na localidade. Buscou-se, ainda, observar as condições gerais do contexto pandêmico. Há imprecisão no que diz respeito à efetiva velocidade de transmissão e infecção, ainda que cercada de algum grau de mensuração, meses após o início declarada pandemia, implica diretamente na observação dos padrões locais respectivos.

A segunda abordagem foi mediada pela solução de curto prazo das equações do modelo SIR. Tal solução forneceu o típico crescimento exponencial que se mostrou em concordância com os dados observados até o dia 14 de abril permitindo a obtenção de uma estimativa preliminar de $R_{0}$ entre [1.340, 3.271]. Nos dias subsequentes nota-se uma discrepância abrupta e precoce do fit exponencial em decorrência das medidas de isolamento adotadas.

$\mathrm{Na}$ terceira abordagem aplicou-se o modelo vSIR para os dados reais de infectados. Foi verificado que a taxa básica de reprodução $R_{0}$ para o Amapá é de 2.11 evidenciando que a epidemia neste estado encontra-se em plena expansão, este fato se agrava ainda mais com as informações de isolamento social que mostra que o Estado, sob a luz do primeiro decreto de quarentena chegou a ter $56 \%$ de seus cidadãos isolados em 05 de abril, porém, esse número caiu para $43 \%$ em 12 de abril.

Para que haja uma redução de para o nível de controle da epidemia $\left(R_{0}<1\right)$ é necessário que a taxa de transmissão $\beta$ que hoje está em $\sim 0.216$ sofra uma redução em mais de $53 \%$ para que se tenha $R_{0}$ sob controle, o que somente é possível com 
ações rigorosas de controle de dispersão da população para reduzir os contatos entre os indivíduos, desacelerando assim a interação entre suscetíveis e infecciosos.

\section{AGRADECIMENTOS}

Os autores agradecem especialmente a Milan Batista da University of Ljubljana pelas prestimosas contribuições no uso do open source code para o Matlab e ao apoio da CAPES e do CNPQ no desenvolvimento deste trabalho, através da concessão de bolsa de Doutorado e de amparo à pesquisa.

\section{REFERÊNCIAS}

ALIMOHAMADI, Yousef; TAGHDIR, Maryam; SEPANDI, Mojtaba. The estimate of the basic reproduction number for novel coronavirus disease (covid-19): A systematic review and meta-analysis. Journal of Preventive Medicine and Public Health, 2020. Disponível em: <https://www.jpmph.org/upload/pdf/jpmph-20-076.pdf> Acesso em: $01 / 05 / 2020$

AMAPÁ. Painel Coronavírus. [internet].2020a. Disponível em: <http://painel.corona.ap.gov.br/ > Acesso em: 10/05/2020

AMAPÁ. Superintendência de Vigilância em Saúde - SVC. 2020b. Disponível em: <https://svs.portal.ap.gov.br/coronavirus> Acesso em: 14/04/2020.

BATISTA, Milan. fitVirusCOVID19. MATLAB Central File Exchange. [Internet]. 2020. Disponível em: <https://www.mathworks.com/matlabcentral/fileexchange /74658fitviruscovid19> Acesso em 15/05/2020.

BROOKS, Samantha K.; WEBSTER, Rebecca K.; SMITH, Louise E.; WOODLAND, Lisa.; WESSELY, Simon; GREENBERG, Neil. RUBIN, Gideon James. The psychological impact of quarantine and how to reduce it: rapid review of the evidence. The Lancet. London, Uk, v. 395, p.912-920, mar. 2020. DOI:https://doi.org/10.1016/S0140-6736(20)30460-8 
BUITRAGO-GARCIA, Diana C.; EGLI-GANY, Dianne; COUNOTTE , Michel J.; HOSSMANN, Stefanie; IMERI, Hira; SALANTI, Georgia. LOW, Nicola. The role of asymptomatic SARS-CoV-2 infections: rapid living systematic review and metaanalysis. medRxiv, 2020. Disponível em: $<$ https://www.medrxiv.org/content/10.1101/2020.04.25.20079103v1> Acesso em: $10 / 05 / 2020$

DANDEKAR, R.; BARBASTATHIS, G. Neural Network aided quarantine control model estimation of COVID spread in Wuhan, China. 2020. Disponível em: <https://arxiv.org/abs/2003.09403> Acesso em: 10/05/2020.

DELAMATER, Paul L.; STREeT, Erica J.; LESLIE, Timothy F., YANG, Y. Tony; JACOBSEN, Kathryn H. Complexity of the Basic Reproduction Number (R0). Emerg Infect Dis 2019;25:1-4 PMC6302597

FERGUSON, Neil M.; GHANI, Azra C.; WALKER, Patrick G. T.; WHITTAKER, Charles; WATSON, Oliver; BAGUELIN, Marc; AINSLIE, Kylie E. C. et al.. The Global Impact of COVID-19 and Strategies for Mitigation and Suppression. 26 mar 2020. Imperial College London COVID-19 Response Team. Disponível em: $<$ https://www.imperial.ac.uk/media/imperial-college/medicine/mrc-gida/2020-03-26COVID19-Report-12.pdf> Acesso em: 14/05/2020.

HARKO, Tiberiu; LOBO, Francisco S. N.; MAK, M. K. Exact analytical solutions of the Susceptible-Infected-Recovered (SIR) epidemic model and of the SIR model with equal death and birth rates. Applied Mathematics and Computation. 236: 184194, 2014. Disponível em: <https://arxiv_org/abs/1403.2160> Acesso em: 10/05/2020

HETHCOTE, Herbert W. The mathematics of infectious diseases. SIAM Review, v. 42, n. $4, \quad$ p. $599-653,2000 . \quad$ Disponível em: <https://epubs.siam.org/doi/abs/10.1137/s0036144500371907> Acesso em: $10 / 05 / 2020$

IBGE. Cidades e Estados: Amapá. 2020. [internet]. Disponível em: $<$ https://www.ibge.gov.br/cidades-e-estados/ap.html> Acesso em: 20.04.20 
IN LOCO. Mapa de Dados. 2020. [internet]. Disponível <https://mapabrasileirodacovid.inloco.com.br> Acesso em 03/05/2020.

MRAD, Assaad; BONETTI, Sara; MANOLI, Gabriele; PAROLARI, Anthony J. Global convergence of COVID-19 basic reproduction number and estimation from early-time SIR dynamics. MedRxiv. 2020. Disponível em: $<$ https://www.medrxiv.org/content/10.1101/2020.04.10.20060954v2> Acesso em: 01/05/2020

LI, Ruiyun; PEI, Sen; CHEN, Bin; YIMENG, Canção; ZHANG, Tao; YANG, Wan; SHAMAN, Jeffrey. Substantial undocumented infection facilitates the rapid dissemination of novel coronavirus (SARS-CoV-2). Science, v. 368, n. 6490, p. 489493, 2020. Disponível em: <https://science.sciencemag.org/content/368/6490/489> Acesso em: 10/05/2020

LIU, Ying; GAYLE, ALBERT A.; WILDER-SMITH, Annelies; ROCKLÖV Joacim. The reproductive number of COVID-19 is higher compared to SARS coronavirus. Journal of travel medicine, 2020. Disponível em: $<$ https://academic.oup.com/jtm/article/27/2/taaa021/5735319> Acesso em: $10 / 05 / 2020$

MINISTÉRIO DA SAÚDE. Sobre a Doença Covid-19. Brasília. 2020. [internet]. Disponível em <https://coronavirus.saude.gov.br/sobre-a-doenca> Acesso em: $14 / 05 / 2020$

MINISTÉRIO DA SAÚDE. Síntese de casos, óbitos, incidência e mortalidade. Brasília. 2020a. [internet]. Disponível em: <https://covid.saude.gov.br/> Acesso em 15/05/2020.

ORGANIZAÇÃO MUNDIAL DA SAÚDE. Coronavirus disease 2019 (COVID-19) Situation Report - 46. Disponível em <https://www.who.int/docs/defaultsource/coronaviruse/situation-reports/20200306-sitrep-46-covid-

19.pdf?sfvrsn=96b04adf_4\#: :text=For\%20COVID\%2D19\%2C,infections\%2C\%20re quiring\%20ventilation.> Acesso em 16/05/2020 
PIRES, L.N.; CARVALHO, L.; XAVIER, L.L. COVID-19 e Desigualdade no Brasil. Centro Brasileiro de Estudos da Saúde. Disponível em < http://cebes.org.br/2020/04/covid-19-e-desigualdade-no-brasil/>. Acesso em 16/05/2020.

PRADO, Marcelo; BASTOS, Leonardo; BATISTA, Amanda; ANTUNES, Bianca; BAIÃO, Fernanda, MAÇAIRA, Paula; HAMACHER, Silvio; BOZZA, Fernando. Nota Técnica 7 NOIS/Puc-Rio: Análise de subnotificação do número de casos confirmados da COVID-19 no

Brasil. <http://www.supersuporte.com/myRpubs/NT7_Subnotificacao_notaDia11-abr2020.pdf>, Acessado em: 14.05.2020.

PRADO, Marcelo; BASTOS, Leonardo; BATISTA, Amanda; ANTUNES, Bianca; BAIÃO, Fernanda, MAÇAIRA, Paula; HAMACHER, Silvio; BOZZA, Fernando. Nota Técnica 7 NOIS/Puc-Rio: Evolução da epidemia de COVID-19 no Brasil até 04 de maio de 2020. <https://drive.google.com/file/d/17a9F6WEmCoihJmXF3KMHEl1jWo51xarz/view>, Acesso em: 14/05/2020

READ, Jonathan M.; BRIDGEN, Jessica R. E.; CUMMINGS, Derek A. T. HO, Antonia; JEWELL, Chris P. Novel coronavirus 2019-nCoV: early estimation of epidemiological parameters and epidemic predictions. MedRxiv, 2020. Disponível em: <https://www.medrxiv.org/CONTENT/10.1101/2020.01.23.20018549V2> Acesso em $10 / 05 / 2020$

TODA, Alexis Akira. Susceptible-infected-recovered (sir) dynamics of covid-19 and economic impact. ArXiv:2003.11221, 2020. Disponível em: <https://arxiv.org/abs/2003.11221 > Acesso em: 09/05/2020

ZHANG, Yuan; YOU, Chong; CAI, Zhenghao; SUN, Jiarui; HU, Wenjie; ZHOU, XiaoHua. Prediction of the COVID-19 outbreak based on a realistic stochastic model. medRxiv, 2020. Disponível em: 
<https://www.medrxiv.org/content/10.1101/2020.03.10.20033803v1> Acesso em: 09/05/2020

ZHONG, Linhao; MU, Lin;LI, Jing; WANG, Jiaying; YIN, ZHE; LIU, Darong. Early prediction of the 2019 novel coronavirus outbreak in the mainland china based on simple mathematical model. leee Access, v. 8, p. 51761-51769, 2020. Disponível em: <https://ieeexplore.ieee.org/document/9028194> Acesso em: 09/05/2020

ZORZETTO, R. A segunda onda do coronavírus. PESQUISA FAPESP, 2020. Disponível em <https://revistapesquisa.fapesp.br/2020/03/30/a-segunda-onda-docoronavirus/> Acesso em: 09/05/2020

\section{APÊNDICE - REFERÊNCIA DE NOTA DE RODAPÉ}

11. http://www2.unifap.br/matematicaplicada/pagina-exemplo/

Enviado: Maio, 2020.

Aprovado: Maio, 2020. 